\title{
Debatendo a ética na pesquisa com seres humanos por meio de um júri simulado: relato de experiência
}

\author{
Debating ethics in research with humans by a simulated jury: \\ experience report
}

\author{
Debate de ética en la investigación con seres humanos por medio de un jurado \\ simulado: \\ relato de experiencia
}

\author{
Janaína Pereira Pretto Carlesso ${ }^{2}$
}

\begin{abstract}
Resumo: O presente estudo visa apresentar um debate sobre a ética na pesquisa com seres humanos por meio de um júri simulado. A atividade foi realizada com acadêmicos do curso de Psicologia de uma instituição privada de ensino superior localizada na cidade de Santa Maria-RS. Primeiramente os alunos foram instruídos teoricamente com uma aula expositiva que abordou a ética na pesquisa com seres humanos. Após a etapa da teorização foi proposto aos alunos que assistissem ao filme "A Experiência" (2001). Uma turma de 23 alunos foi dividida de acordo com as funções específicas de cada integrante de um julgamento para realização da atividade. Constatou-se nas argumentações dos alunos a relação da teoria com a prática, como também a postura ética, criatividade e a exposição do senso crítico. Conclui-se que o Júri simulado possibilita a argumentação no contexto da sala de aula, sendo considerado um recurso didático importante e inovador para promover aprendizagens significativas.
\end{abstract}

Palavras-chave: Metodologia ativa. Júri simulado. Ética na pesquisa.

\begin{abstract}
The present study aims to present a debate on ethics in research with human beings through a simulated jury. The activity was carried out with academics of the Psychology course of a private institution of higher education located in the city of Santa Maria-RS. First the students were theoretically instructed with an expository class that approached the ethics in the research with human beings. After the theorizing stage, the students were invited to watch "The Experience" (2001). A class of 23 students was divided according to the specific functions of each member of a trial to carry out the activity. The students' arguments were related to the relationship between theory and practice, as well as ethical posture, creativity and exposure of the critical sense. It is concluded that the simulated jury allows the argumentation in the context of the classroom, being considered an important and innovative didactic resource to promote meaningful learning.
\end{abstract}

Keywords: Active methodology. Simulated jury. Ethics in research.

Resumen: El presente estudio pretende presentar un debate sobre la ética en la investigación con seres humanos a través de un jurado simulado. La actividad fue realizada con académicos del curso de Psicología de una institución privada de enseñanza superior ubicada en la ciudad de Santa Maria-RS. Primero los alumnos fueron instruidos teóricamente con una clase expositiva que abordó la ética en la investigación con seres humanos. Después de la etapa de la teorización fue propuesto a los alumnos que asistieran a la película "La Experiencia” (2001). Una clase de 23 alumnos fue dividida de acuerdo con las funciones específicas de cada integrante de un juicio para la realización de la actividad. Se constató en las argumentaciones de los alumnos la relación de la teoría con la práctica, así como la postura ética, la creatividad y la exposición del sentido crítico. Se concluye que el Jurado simulado posibilita la argumentación en el contexto del aula, siendo considerado un recurso didáctico importante e innovador para promover aprendizajes significativos.

Palabras clave: Metodología activa. Jurado simulado. Ética en la investigación.

\footnotetext{
${ }^{1}$ Submetido em: 20 dez. 2018 - Aceito em: 01 julho 2019 - Publicado em: 20 dez. 2019

${ }^{2}$ Universidade Franciscana (UFN) - E-mail: janapcarlesso@yahoo.com.br 


\section{Introdução}

Atualmente ao refletir sobre a perspectiva da docência no ensino superior, diferentes linhas de trabalho (processo de avaliação, metodologias, currículo etc.) têm sido discutidas e colocadas em prática nas diversas áreas de conhecimentos como forma de revisão de uma prática docente ainda muito comum nos cursos de graduação: aquela que se alicerça na ideia de professor como único participante ativo da sala de aula; aquele que detém o conhecimento e que deve fazer a transmissão para os alunos de forma linear, fundamentalmente baseada em textos e aulas teóricas excessivamente expositivas (VEIGA; FONSECA, 2018).

Carlini (2006) e Kalatzis (2008) ressaltam a necessidade de superação de práticas tradicionais de ensino e de aprendizagem no ensino superior, particularmente, pelo fato das mesmas frente a esta nova realidade pouco contribuir para a formação de profissionais para o atual mercado de trabalho. Mercado esse que tem demandado cada vez mais profissionais que apresentem além do conhecimento científico um comportamento e atitude adequados, ou seja, a capacidade de resolver problemas, de comunicar-se de forma efetiva, tomar decisões, trabalhar em equipe, aprender de forma independente e de adaptar-se às diversas situações que fazem parte do cotidiano do profissional.

A metodologia ativa segundo Bordenave e Pereira (2007) é uma concepção educativa que estimula processos de ensino-aprendizagem crítico-reflexivos, no qual o educando participa e se compromete com seu aprendizado. O método propõe a elaboração de situações de ensino que promovam uma aproximação crítica do aluno com a realidade; a reflexão sobre problemas que geram curiosidade e desafio; a disponibilização de recursos para pesquisar problemas e soluções; a identificação e organização das soluções hipotéticas mais adequadas à situação e a aplicação dessas soluções. Segundo Berbel (2011, p. 29) as metodologias ativas "baseiam se em formas de desenvolver o processo de aprender, utilizando experiências reais ou simuladas, visando às condições de solucionar, desafios advindos das atividades essenciais da prática social".

O júri simulado estratégia de ensinagem apresentada nesse estudo, segundo Abepirense et al. (2014), consiste em uma atividade multidisciplinar em que se simula um tribunal judiciário no qual os participantes assumem funções anteriormente estabelecidas. É uma estratégia já utilizada há algum tempo em escolas e universidades, pois permite que questões divergentes sejam discutidas, desenvolvendo o senso crítico dos alunos e também permite que os mesmos ampliem suas habilidades e competências com relação à capacidade de falar em público, à organização de ideias, à argumentação, à persuasão.

Segundo Anastasiou e Alves (2009) um júri-simulado é uma simulação em que, a partir de um assunto divergente, são apresentados argumentos de defesa e de acusação a esse problema. $\mathrm{O}$ grupo é levado à análise e à avaliação do fato proposto por meio de objetividade e realismo, "à crítica construtiva de uma situação e à dinamização do grupo para estudar profundamente um tema real" (ANASTASIOU; ALVES, 2009, p. 92). A partir de tais considerações, este estudo visa apresentar uma prática docente com o uso de metodologias ativas no ensino superior, por meio de um júri simulado. 


\section{Metodologias ativas no ensino}

As metodologias ativas de ensino e aprendizagem conforme Cotta et al. (2012, p. 788), se baseiam em

estratégias de ensino fundamentadas na concepção pedagógica crítico-reflexiva, que permitem uma leitura e intervenção sobre a realidade, favorecendo a interação entre os diversos atores e valorizando a construção coletiva do conhecimento e seus diferentes saberes e cenários de aprendizagem.

Segundo Borges e Alencar (2014, p. 119-120), as metodologias ativas são importantes recursos para a formação crítica e reflexiva dos estudantes por meio de processos de ensino e aprendizagem construtivistas que relevam o contexto contemporâneo da docência quando favorecem a autonomia e a curiosidade dos educandos, de modo a estimular "tomadas de decisões individuais e coletivas, advindos das atividades essenciais da prática social e em contextos do estudante".

Moreira e Ribeiro (2016) apontam que as metodologias ativas, envolvem os estudantes e os engajam ativamente em todos os processos de sua aprendizagem, trazem benefícios como o protagonismo estudantil, a apreensão das informações mediadas, habilidades comunicacionais, habilidades de raciocínio avançadas, trabalho em equipe, motivação, novos recursos de aprendizagem e respeito aos vários estilos de aprendizagem.

Segundo Barbosa e Moura (2013, p. 2), as metodologias ativas são aquelas que apresentam as seguintes características:

1. Demandam e estimulam a participação do aluno, envolvendo-o em todas as suas dimensões humanas: sensório-motor, afetivo-emocional, mental-cognitiva.

2. Respeitam e estimulam a liberdade de escolha do aluno diante dos estudos e atividades a serem desenvolvidas, possibilitando a consideração de múltiplos interesses e objetivos.

3. Valorizam e se apoiam na contextualização do conhecimento, imprimindo um sentido de realidade e utilidade nos estudos e atividades desenvolvidas.

4. Estimulam as atividades em grupos, possibilitando as contribuições formativas do trabalho em equipe.

5. Promovem a utilização de múltiplos recursos culturais, científicos, tecnológicos que podem ser providenciados pelos próprios alunos no mundo em que vivemos.

6. Promovem a competência de socialização do conhecimento e dos resultados obtidos nas atividades desenvolvidas.

As metodologias ativas segundo Berbel (2011) têm o potencial de despertar a curiosidade, à medida que os alunos se inserem na teorização e trazem elementos novos, ainda não considerados nas aulas ou na própria perspectiva do professor. Quando acatadas e analisadas as contribuições dos alunos, valorizando-as, são estimulados os sentimentos de envolvimento, percepção de competência e de pertencimento, além da persistência nos estudos. Baseiam-se em formas de desenvolver o processo de aprender, utilizando experiências reais ou simuladas, visando às condições de solucionar, com sucesso, desafios advindos das atividades essenciais da prática social, em diferentes contextos.

Acerca do exposto acima Mitre et al. (2008) apontam que as metodologias ativas utilizam a problematização como estratégia de ensino e aprendizagem, com o objetivo de 
estimular o discente a refletir e agir, pois diante do problema, ele se detém, examina, reflete, relaciona a sua história e passa a ressignificar suas descobertas. Ainda segundo os autores, a problematização pode levar o aluno ao contato com as informações e à produção de conhecimento, com a finalidade de solucionar os impasses e promover o seu próprio desenvolvimento. Aprender por meio da problematização e/ou da resolução de problemas de sua área, portanto, é uma das possibilidades de envolvimento ativo dos alunos em seu próprio processo de formação.

O júri simulado, objeto de análise desse estudo, conforme Anastasiou e Alves (2009), é a reprodução de uma situação em que são apresentados argumentos de defesa e de acusação para a análise de um problema. Essa estratégia envolve um grupo razoável de alunos em sua organização. A distribuição dos papéis é feita por analogia ao julgamento penal por intermédio das seguintes equipes: promotoria, defesa, conselho de sentença e plenário. Dessa forma, durante a realização da atividade, os demais alunos também podem ser incluídos como participantes.

A estratégia de um júri simulado leva em consideração a possibilidade da realização de inúmeras operações de pensamento, como: defesa de ideias, argumentação, julgamento, tomada de decisão etc. Sua preparação é de intensa mobilização, pois, além de ativar a busca do conteúdo em si, os aparatos de outro ambiente (roupas, mobiliário etc.) oportunizam um envolvimento de todos para além da sala de aula. A estratégia pode ainda ser regada de espírito de dramaturgia, o que deixa a atividade interessante para todos, independentemente da função que desenvolverão na apresentação final. Essa estratégia envolve todos os momentos da construção do conhecimento, da mobilização à síntese, pela sua característica de possibilitar o envolvimento de um número elevado de estudantes (ANASTASIOU; ALVES, 2009).

\section{Relato de experiência}

\section{Preparação do Júri Simulado}

Para debate e discussão das questões éticas da pesquisa científica com seres humanos foi utilizada em sala de aula a metodologia ativa - Júri simulado. Primeiramente, os acadêmicos do curso de Psicologia do $3^{\circ}$ semestre de uma instituição privada de ensino superior localizada na cidade de Santa Maria-RS, foram instruídos teoricamente com uma aula expositiva que abordou a temática da ética na pesquisa com seres humanos, apresentando os artigos da Resolução 466/2012 do Conselho Nacional de Saúde. A Resolução traz termos e condições a serem seguidos em todas as pesquisas que envolvem seres humanos. Aborda requisitos do Sistema de avaliação ética brasileiro, compondo um sistema que utiliza mecanismos, ferramentas e instrumentos próprios de inter-relação que visa à proteção dos participantes de pesquisa (BRASIL, 2013).

A Organização Mundial de Saúde (OMS) define como pesquisa com seres humanos qualquer atividade de ciência social, biomédica, comportamental ou epidemiológica que 
envolva coleta sistemática ou análise de dados no intento de gerar novo conhecimento, no qual seres humanos: a) sejam expostos a manipulação, intervenção, observação ou outra interação com investigadores, seja diretamente ou a partir de alguma alteração no seu ambiente; b) tornem-se individualmente identificáveis pela coleta, preparação ou uso de material biológico ou médico ou de outros registros do investigador (OMS, 2018).

Após a teorização em sala de aula sobre a temática, foi proposto aos alunos que assistissem ao filme "A Experiência" (2001), que retrata a condução de um experimento com seres humanos, a qual uma equipe de cientistas arregimenta 20 presos para uma experiência psicológica em troca de um prêmio em dinheiro. Os prisioneiros são divididos em dois grupos: oito deles fazem o papel de guardas e os outros 12, de internos. As cobaias são isoladas numa área da penitenciária onde certas regras devem ser obedecidas e mantidas pelos guardas. No início, a camaradagem reina no ambiente, mas, a violência não tarda a explodir quando um ex-repórter disfarçado de preso lidera um motim. Os guardas reagem com brutalidade crescente. O conflito se agrava com a morte de um dos presos e a captura dos cientistas que criaram o projeto.

\section{Organização e efetivação do Júri}

A turma de 23 alunos foi dividida de acordo com as funções específicas de cada profissional e/ou integrante de um julgamento: juiz, réus, advogados de defesa, advogados de acusação - promotoria, testemunhas e jurados. Após a composição dos membros do júri foi lançada a seguinte questão problema aos alunos: "os pesquisadores que conduziam o experimento com seres humanos retratado no filme "A Experiência" cumpriam as normas éticas conforme a CNS 466/2012?" Diante da questão exposta em sala de aula, os alunos tiveram cerca de uma semana para pesquisar, refletir, organizar seus respectivos grupos (no caso dos advogados de defesa e acusação) para elaborar suas teses, para que no dia da atividade pudessem argumentar, testemunhar, apresentar "provas". Nesse contexto, o professor possibilita ao aluno se colocar como sujeito de sua aprendizagem, instigando-os a buscar estratégias, pesquisar autores diversos referente à temática estudada para a realização da atividade (FREIRE, 1996).

Cabe apontar segundo Gadotti (1999) e Freire (2005), que o professor além de explicitar cada etapa que deve ser cumprida pelo aluno precisa estar presente no decorrer de todo o processo de busca de resposta para o problema, deixando de lado o papel tradicional de detentor do conhecimento para colocar em prática o diálogo em uma perspectiva horizontal. Acerca disso, Ribeiro (2010) destaca que o aluno assume um papel ativo em sua aprendizagem a partir de responsabilidades explicitadas pelo professor e, o docente, deixa de ser o transmissor e deve adotar a postura de facilitador e orientador, mediando à integração dos conceitos e das habilidades necessárias para a resolução de problemas.

A atividade foi realizada no Salão do Júri da instituição privada de ensino, o júri simulado foi conduzido pelo juiz que abriu a sessão lançando a questão-problema aos participantes. Os réus (3) representavam os pesquisadores que conduziram o experimento 
com seres humanos retratado no filme. Os advogados de defesa apresentaram argumentos que apontavam a responsabilidade ética cumprida pelos pesquisadores do estudo, culpabilizando os guardas participantes do experimento como responsáveis pelos atos inadequados e de violência durante o andamento da pesquisa. A defesa também apresentou testemunhas (estas contracenadas pelos alunos como pessoas que se encontravam no recinto do experimento realizando a limpeza do local).

A promotoria apresentou acusações contra os réus buscando condená-los, por meio de argumentos coerentes baseados na Resolução 466/2012, salientando a falta de compromisso ético dos pesquisadores com os participantes da pesquisa. Os jurados responsáveis por analisar os fatos expostos e, ao final, dar o veredicto, acompanharam todo o processo e a seguir votaram que os réus eram culpados definindo a pena. Após todo o caso debatido, o juiz decidiu a sentença final, e os réus foram condenados, por inflingir às diretrizes e normas regulamentadoras de pesquisas envolvendo seres humanos conforme Resolução 466 de 12 de dezembro de 2012. O respeito pela dignidade humana e pela especial proteção, devida aos participantes das pesquisas científicas envolvendo seres humanos, não foi cumprida no experimento retratado no filme "A Experiência".

\section{Resultados e discussões}

No relato de experiência exposto teve-se a finalidade de apresentar a importância de diversificar as práticas de ensino no âmbito da sala de aula, discutindo a relevância do uso de metodologias ativas por meio de um júri simulado. Observou-se durante a atividade realizada que os objetivos foram atingidos, pois foi possível constatar no desempenho dos alunos em suas argumentações a relação da teoria (artigos da Resolução 466/2012) com a prática (análise fílmica), e muito, além disso, postura ética, criatividade, exercício da expressão e o raciocínio, a exposição do senso crítico. Real e Menezes (2007, p. 96) descrevem o Júri Simulado como uma dinâmica para estimular a "reflexão dialogada, o pensamento crítico e a exposição e o respeito às diferenças e a tomada de posição a partir de argumentos sólidos".

Veiga e Fonseca (2018) ressaltam que o papel do aluno deixa de ser visto como um agente passivo que recebe tudo pronto do professor e passa a atuar de forma ativa no processo de aprendizagem. O aluno instigado pelo professor vai em busca por conta própria, pesquisa fontes para elaborar seus argumentos, seus pontos de vista referente à temática estudada, tornando-se o principal agente do seu processo de aprendizado, trajetória percorrida com maior prazer, motivação e realização, que possibilitará maior introjeção do conteúdo trabalhado. Segundo Diesel, Marchesan e Martins (2016), as estratégias de ensino norteadas pelo método ativo têm como características principais: o aluno como centro do processo, a promoção da autonomia do aluno, a posição do professor como mediador, ativador e facilitador dos processos de ensino e de aprendizagem e o estímulo à problematização da realidade, à constante reflexão e ao trabalho em equipe.

Lascombe et al. (2019) apontam que os docentes de diferentes níveis de ensino devem investir em metodologias ativas em sala de aula, utilizando os filmes, como também seriados, 
documentários como ferramentas de análise que possam auxiliar na aprendizagem dos alunos. Os autores ressaltam ainda a importância de inovar as atividades e estimular os acadêmicos a problematizar realidades mesmo que seja por meio da ficção. Essas ações possibilitam a identificação de situações-problemas que oportunizam o estudante a pensar e refletir, estimulando o raciocínio crítico, e os conduz a um processo de construção de novos sentidos e conhecimentos em relação à realidade observada, percurso importante para que se consolide um aprendizado significativo. Acerca disso, cabe apontar que além de possibilitar a aprendizagem no âmbito da sala de aula, o uso de filmes como dispositivo de ensino, também possibilita aos educandos subsídios para a construção e reconstrução de sua subjetividade diante da realidade observada e analisada. Em um estudo realizado por Duarte e Carlesso (2019), as autoras ressaltam a relevância do uso da análise fílmica para compreensão do comportamento humano diante de situações cinematográficas.

Segundo Garcia (2015), o cinema favorece tanto o aprofundamento quanto a proposição de novas formas de questionamento que perpassam as diversas áreas do conhecimento relativas à cultura, permitindo pensar temas como, por exemplo, a compreensão dos múltiplos aspectos relacionados com a constituição da subjetividade no contemporâneo.

Cabe destacar que os alunos em processo de formação em qualquer nível de ensino, do fundamental ao superior, devem ser instigados pelo professor a problematizar, refletir, criticar, e as metodologias ativas no âmbito da sala de aula podem oportunizar e ampliar o campo de experiência subjetiva do aluno, fatores importantes que poderão contribuir nos processos de subjetivação do indivíduo, tendo reflexos positivos no aspecto intelectual.

\section{Considerações finais}

O estudo apontou que o uso do Júri Simulado é uma importante estratégia de aprendizagem no ensino superior, capaz de promover transformações na prática docente, tornando a sala de aula mais envolvente para a díade professor-aluno, resultando em satisfação no desempenho da prática docente e melhora do nível do aprendizado dos educandos e, por fim, motivação para ambos envolvidos nesse processo.

Cabe destacar que o professor da era contemporânea precisa ir muito além do domínio do conteúdo teórico, é necessário tornar a sala de aula num ambiente inovador de aprendizagem. A técnica de ensino relatada nesse estudo proporcionou aos acadêmicos uma reflexão crítica e dialogada diante do problema, estimulando-os ao debate de ideias, à discussão, o posicionamento crítico, favorecendo a capacidade de expressão e argumentação, além de possibilitar a tomada de decisão e o trabalho em equipe. Acerca disso, ressalta-se que durante a atuação dos alunos na atividade, foi possível avaliar claramente as potencialidades de cada aluno, tornando o processo de avaliação mais prático para o docente.

Aponta-se que a concretização dessa atividade só poderia ser realizada com a participação ativa e atuante dos alunos, sendo os mesmos a "peça fundamental" para o desenvolvimento do júri, sem eles não seria possível alcançar os objetivos da atividade 
proposta, que foi sensibilizar os estudantes sobre os aspectos éticos da pesquisa científica com seres humanos.

Entretanto, cabe destacar também a importância do papel do professor no planejamento do júri simulado, tanto em relação à escolha da temática, à organização e à coordenação da atividade, estratégia de ensino que exige planejamento e envolvimento por parte do professor. Acerca disso, cabe destacar que o Júri simulado como técnica de ensinagem possibilita a argumentação no contexto da sala de aula, sendo considerado um recurso didático importante e inovador para promover argumentações e desenvolver as habilidades argumentativas dos estudantes.

\section{Referências}

ABEPIRENSE, Pacita Geovana Gama de Sousa et al. O uso de metodologias ativas na formação do profissional Enfermeiro - Tribunal do Juri Simulado: uma experiência de sucesso. In: Congresso Iberoamericano de Ciencia, Tecnología, Innovación y Educación. Buenos Aires, Argentina, 2014.

ANASTASIOU, Léa das Graças Camargos; ALVES, Leonir Pessati. Estratégias de ensinagem. In: ANASTASIOU, Léa das Graças Camargos. Processos de ensinagem na universidade: pressupostos para as estratégias do trabalho em aula. 5. Ed. Joinville, SC: Univille, 2009. p. 67-100.

BARBOSA, Eduardo Fernandes; MOURA, Dácio Guimarães de. Metodologias ativas de aprendizagem na educação profissional e tecnológica. Boletim técnico do SENAC. Rio de Janeiro, v. 39, n. 2, p. 48-67, maio/ago. 2013.

BERBEL, Neusi Aparecida Navas. As metodologias ativas e a promoção da autonomia de estudantes. Semina: Ciências Sociais e Humanas. Londrina, v. 32, n. 1, p. 25-40, jan./jun. 2011.

BORDENAVE, Juan Díaz; PEREIRA, Adair Martins. Estratégias de ensino-aprendizagem. 28 ed. Petrópolis: Vozes, 2007.

BORGES, Tiago Silva; ALENCAR, Gidélia. Metodologias ativas na promoção da formação crítica do estudante: o uso das metodologias ativas como recurso didático na formação crítica do estudante do ensino superior. Cairu em Revista. Salvador, ano 3, n. 4, p. 119-143, jul./ago. 2014.

BRASIL. Ministério da Saúde. Conselho Nacional de Saúde. Resolução n. 466, de 12 de dezembro de 2012. Aprova normas regulamentadoras de pesquisas envolvendo seres humanos. Brasília: Diário Oficial da União, 2013.

CARLINI, Angélica Luciá. Aprendizagem baseada em problemas aplicada ao ensino de direito: projeto exploratório na área de relações de consumo. 2006. 295 f. Tese (Doutorado em Educação) - Pontifícia Universidade Católica de São Paulo, São Paulo, 2006. 
COTTA, Rosângela Minardi Mitre et al. Construção de portfólios coletivo em currículos tradicionais: uma proposta inovadora de ensino-aprendizagem. Ciência e Saúde Coletiva. Rio de Janeiro, v. 17, n. 3, p.787-796, mar. 2012.

DIESEL, Aline; MARCHESAN, Michele Ross; MARTINS, Silvana Neumann.

Metodologias ativas de ensino na sala de aula: um olhar de docentes da educação profissional Técnica de nível médio. Signos. Lajeado, ano 37, n. 1, p. 153-169, 2016.

DUARTE, Indianandra Thomasi; CARLESSO, Janaína Pereira Pretto. Psicanálise, Cinema e Subjetividade: como a sétima arte interfere na construção e reconstrução da subjetividade. Research, Society and Development. Itabira, MG, v. 8, n. 4, e2384820, 2019.

FREIRE, Paulo. Pedagogia da autonomia: saberes necessários à prática educativa. 25 ed. São Paulo: Paz e Terra, 1996.

FREIRE, Paulo. Pedagogia do oprimido. Rio de Janeiro: Paz e Terra, 2005.

GARCIA, Mauricio Lourenção. Cuidado em saúde: abordagem clínico-institucional junto à população em situação de vulnerabilidade social. Projeto de estágio do curso de Psicologia da Universidade Federal de São Paulo, Campus Baixada Santista, Santos, 2015.

GADOTTI, Moacir. Convite à leitura de Paulo Freire. São Paulo: Scipione, 1999.

KALATZIS, Adriana Casale. Aprendizagem baseada em problemas em uma plataforma de ensino a distância com apoio dos estilos de aprendizagem: uma análise do aproveitamento dos estudantes de engenharia. 2008. 113 f. Dissertação (Mestrado em Engenharia da Produção) - Escola de Engenharia de São Carlos da Universidade de São Paulo, São Carlos, 2008.

LASCOMBE, Betina et al. Análise do Filme a "Ilha do Medo" sob o olhar da Psicologia Cognitiva. Research, Society e Development. Itabira, MG, v. 8, n. 1, e1681530, jan. 2019.

MITRE, Sandra Minardi et al. Metodologias ativas de ensino-aprendizagem na formação profissional em saúde: debates atuais. Ciência e Saúde Coletiva. Rio de Janeiro, v. 13, supl. 2, p. 2133-2144, dez. 2008.

MOREIRA, Jonathan Rosa; RIBEIRO, Jefferson Bruno Pereira. Prática pedagógica baseada em metodologia ativa: aprendizagem sob a perspectiva do letramento informacional para o ensino na educação profissional. Periódico Científico Outras Palavras. Brasília, v. 12, n. 2, p. 93-114, 2016.

OMS. ORGANIZAÇÃO MUNDIAL DA SAÚDE. Ethics and Health. [Site]. Disponível em: http://www.who.int/ethics/research/en/index.html. Acesso em: 10 dez. 2018.

REAL, Luciane Magalhães Corte; MENEZES, Crediné Silva de. Júri simulado: possibilidade de construção de conhecimento a partir de interações em um grupo. In: MENEZES, Crediné Silva de; CARVALHO, Marie Jane Soares de; NEVADO, Roseane Aragón de (org.). Aprendizagem em rede na educação a distância: estudos e recursos para formação de professores. Porto Alegre: Ricardo Lenz, 2007. p. 93-102. 
RIBEIRO, Luis Roberto de Camargo. Aprendizagem baseada em problemas (PBL): uma experiência no ensino superior. 1 ed. São Carlos, SP: EdUFSCar, 2010.

VEIGA, Léia Aparecida; FONSECA, Ricardo Lopes. O júri simulado como proposta didático-pedagógica para a formação inicial do professor de geografia na perspectiva da aprendizagem baseada em problemas (PBL). Geousp - Espaço e Tempo (online). São Paulo, v. 22, n. 1, p. 153-171, 2018. 